\title{
Dynamin is involved in human epithelial cell vacuolation caused by the Helicobacter pylori-produced cytotoxin VacA
}

Junko Suzuki, Hirohide Ohnishi, Hiroshi Shibata, Akihiro Wada, Toshiya Hirayama, Taroh Iiri, Namiki Ueda, Chiho Kanamaru, Tomohiro Tsuchida, Hirosato Mashima, Hiroshi Yasuda, and Toshiro Fujita

J. Clin. Invest. 107:363-370 (2001).

During the preparation of this manuscript for publication, an error was introduced into the list of authors. The corrected information appears above.

VLA-5 is expressed by mouse and human long-term repopulating hematopoietic cells and mediates adhesion to extracellular matrix protein fibronectin.

Johannes C.M. van der Loo, Xiangli Xiao, Doug McMilin, Kimikazu Hashino, Ikunoshin Kato, and David A. Williams

J. Clin. Invest. 102:1051-1061 (1998).

The peptide concentration on the $\mathrm{x}$-axis of figure 2 should $\mathrm{read} \mathrm{pmol} / \mathrm{cm}^{2}$. The concentrations mentioned in the text and legends, which were based on this figure, should also read $\mathrm{pmol} / \mathrm{cm}^{2}$. The corrected figure and legend appear below.
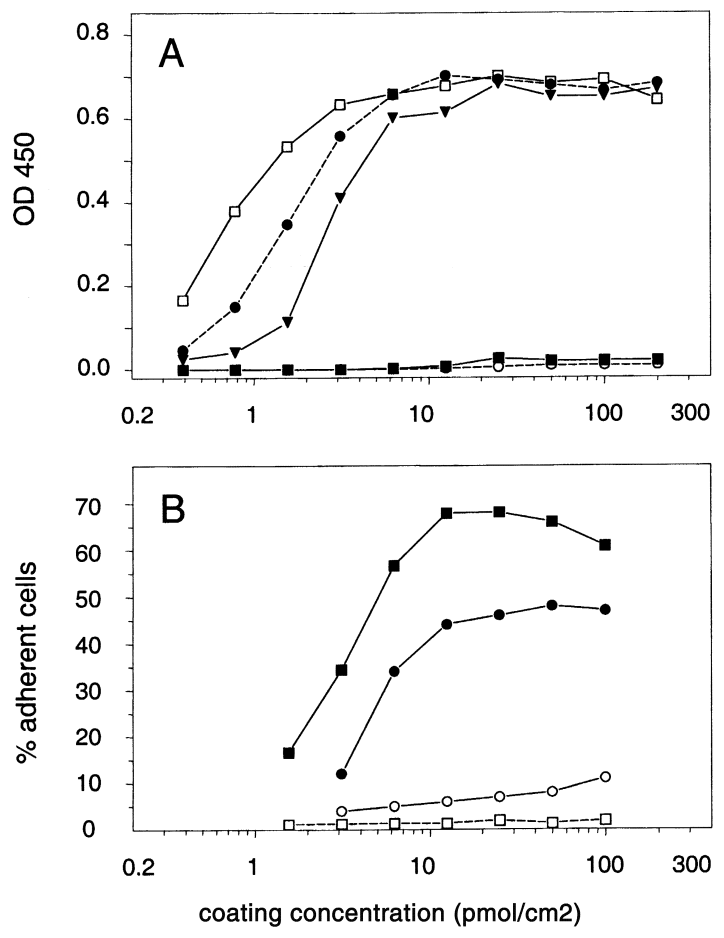

Figure 2

Plastic adherence of FN peptides. Effect of the coating concentration on the absorption of recombinant $\mathrm{FN}$ fragments to nontissue culture-treated plastic $(\mathbf{A})$ and on the subsequent binding of mouse BM cells or human HEL cells (B). Bound FN was detected by ELISA (average of 4 wells/concentration) using antibody FN12-8 (A), which is specific for the CELL-binding domain of FN. (A) Fragment $\mathrm{H}-271$ (filled squares), $\mathrm{C}-274$ (open squares), $\mathrm{CH}-271$ (filled circles), $\mathrm{H}-296$ (open circles), and $\mathrm{CH}-296$ (filled triangles). For clarity, error bars have been omitted. (B) Binding of human HEL cells (squares) or low-density mouse BM cells (circles) to plates coated with $\mathrm{H}-271$ (open symbols) or $\mathrm{CH}-296$ (closed symbols). 